\title{
Microwave Pasteurization of Pre-packaged Carrots
}

Jing Peng ${ }^{\mathrm{a}, \mathrm{b}}$, Juming Tang ${ }^{\mathrm{b}}$, Donglei Luan ${ }^{\mathrm{b}, \mathrm{c}}$, Frank Liu ${ }^{\mathrm{b}}$, Zhongwei Tang ${ }^{\mathrm{b}}$, Feng $\mathrm{Li}^{\mathrm{b}, \mathrm{c}}$, Wenjia Zhang ${ }^{\mathrm{b}}$

${ }^{a}$ College of Food Science and Technology, Nanjing Agricultural University, Nanjing, Jiangsu 210095,

China

${ }^{\mathrm{b}}$ Department of Biological Systems Engineering, Washington State University, Pullman, WA 99164, USA

${ }^{c}$ Department of Food Science and Technology, Shanghai Ocean University, Shanghai 201306, China

Abstract: This research investigated the application of $915 \mathrm{MHz}$ microwaves in pasteurizing pre-packaged vegetables. A specially designed $915 \mathrm{MHz}$ single-mode microwave-assisted pasteurization (MAP) system was used to process carrot cuboids in brine pre-packaged in 8-oz polymer pouches. Gellan gel was formulated and selected as the model food to simulate the real foods processed by the MAP system; heating patterns and cold spots of the pouched samples were detected by a chemical-marker based computer vision method. Two MAP processes $\left(\mathrm{F}_{90^{\circ} \mathrm{C}}=3\right.$ min and $\left.\mathrm{F}_{90^{\circ} \mathrm{C}}=10 \mathrm{~min}\right)$ targeting Clostridium botulinum type E spores were developed and compared with conventional hot water (HW) processes resulting in equivalent microbial safety. Compared with an equivalent HW process, MAP process greatly reduced the total processing time, reduced the cook values and improved quality uniformity of the products. Quality evaluation showed the impacts of MAP processing on each quality attribute of carrot products depended on the specific quality parameter selected. 
Keywords: microwave pasteurization; process development; carrots; cold spot; heating pattern; food quality

\section{Introduction}

The increased public awareness of healthy diet and the needs for ready-to-eat foods make pasteurization an effective method to provide safe convenient foods with high quality. Microwave processing is one of the emerging thermal technologies applied to foods for pasteurization. It takes relatively short heating times (usually several minutes) due to its volumetric heating generated within food materials. The rapid heating results from interaction between the alternating electromagnetic field and dielectric materials, and it overcomes the slow heating of conventional thermal processes depending on conductive and convective heat transfer. Therefore, microwave pasteurization has the potential to produce high quality shelf-stable food products (Tang, 2015).

However, there are very limited publications about systemically design of a microwave pasteurization process for vegetable products, especially using $915 \mathrm{MHz}$ microwaves which can provide deeper penetration depth and, therefore, more uniform heating than $2450 \mathrm{MHz}$ microwaves used by the common domestic ovens. The major considerations for developing a pasteurization process include determining the most resistant pathogen that is likely to survive the process for the food; assessing and validating the required level of inactivation of the target microorganism; and evaluating appropriate storage temperature and shelf life (Peng et al., 2015). For microwave processing, non-uniformity heating caused by the uneven electric field distribution results in the cold and hot spots 
(the lowest and highest thermal energy reception areas) in the processed foods; and the thermal treatment at the coldest location in food package will determine the safety of the process. Thus, it is critical to determine the heating pattern and identify the cold spots in pre-packaged foods processed by microwave heating systems in order to meet the regulation requirements for food safety. Tang (2015) provides a historical overview on the development of $915 \mathrm{MHz}$ single-mode microwave-assisted thermal sterilization and pasteurization systems, including system design, chemical marker method for heating pattern determination, temperature measurement for process development, food quality and shelf-life studies. However, no case study is included to illustrate the complete process design for vegetable pasteurization using the $915 \mathrm{MHz}$ microwave system. Lau and Tang (2002) applied $915 \mathrm{MHz}$ microwaves to pasteurize pickled asparagus in glass bottles in a batch process. The process reduced process time by half and resulted in improved textural quality of the processed products compared with conventional water heating. Koskiniemi et al. (2013) established a pasteurization process to produce shelfstable acidified vegetable packs (broccoli, red bell pepper, and sweet-potato) using continuous $915 \mathrm{MHz}$ microwaves with a rotation apparatus. Good retention of color and texture of the processed vegetable pieces was observed, while no microbial spoilage was detected after 60 -day storage at $30^{\circ} \mathrm{C}$. Both works mentioned above used fiber optic temperature sensors to monitor the temperatures of samples during microwave heating. The fiber optic temperature sensors were reliable and accurate, but not applicable for a continuous process. 
Carrots are one of the most commonly consumed vegetables in the United States, onefourth of which are consumed in processed form, largely canned and frozen (Lucier and Lin, 2007). The objectives of this study were to develop a pilot-scale MAP process for pre-packaged carrots in brine using a $915 \mathrm{MHz}$ single-mode microwave system, and evaluate the quality attributes of the products processed by MAP and HW in equivalent microbial safety basis. This study should provide useful information for future commercial microwave pasteurization applications in vegetable processing.

\section{Materials and Methods}

\subsection{Sample preparation}

The same batch of fresh carrots (Bolthouse Farms, Inc., Bakersfield, CA) were purchased from a local supermarket and stored at $4^{\circ} \mathrm{C}$. Carrots were cut into cuboids $(12 \times 12 \times(6-8)$ mm) using a Hallde Flexi RG-7 dicer (Hicksville, NY) the same day right before processing. A total of $136.5 \pm 0.5 \mathrm{~g}$ carrot cuboids and $90.5 \pm 0.5 \mathrm{~g}$ brine $(0.2 \% \mathrm{NaCl}$ with $0.1 \%$ or $1.4 \% \mathrm{CaCl}_{2}$ in distilled water, w/w, total samples in each pouch) were filled into each 8-oz laminate polymer pouch $(18.5 \times 13.2 \times 1.6 \mathrm{~cm}$, Printpack Inc., Atlanta, GA). The salt $\mathrm{NaCl}$ was added to improve taste, while $\mathrm{CaCl}_{2}$ was a firming agent to retain texture. The ratio of carrots to brine and the percentage of $\mathrm{NaCl}$ came from commercial canned carrot products. The two levels of $\mathrm{CaCl}_{2}$ concentration came from our previous work (Peng et al., 2014); one was based on the FDA regulation for canned carrot products $\left(0.036 \% \mathrm{Ca}\right.$ in the final products), the other one fell into the range of $\mathrm{CaCl}_{2}$ concentration (0.5-2.0\%) typically added to vegetable products in published reports (Rastogi et al., 2008; Smout et al., 2005). All filled pouches were sealed using an 
UltraVac 250 vacuum pouch sealer (KOCH Packaging Supplies Inc., Kansas City, MO) with vacuum setting 2.5 ( -0.85 bar) and sealing time setting 4 ( 2 seconds). Prepared carrot pouches were loaded to the MAP or conventional heating system for processing immediately. The color and texture of the processed samples were measured on the same day of processing; the sample pouches for enzyme and carotenoids assay were stored at $30^{\circ} \mathrm{C}$ until the day of analyses.

\subsection{Thermal processing}

The microwave and conventional thermal treatment levels were selected based on equivalent microbial safety (with the same F-value, the cumulative thermal lethality). For severe pasteurization of low-acid foods which allows a shelf life up to 6 weeks at $5^{\circ} \mathrm{C}$, a 6D process (6-log reduction) of psychrotrophic Clostridium botulinum is suitable; and a process of a minimum cumulative lethality of $\mathrm{F}_{90^{\circ} \mathrm{C}}=10 \mathrm{~min}$ is generally recommended for most foods to achieve this goal (ECFF, 2006; Vervoort et al., 2012). For carrots, the target pathogen under this pasteurization level is non-proteolytic (NP) C. botulinum type E spores (Vervoort et al., 2012). In the current study, $90^{\circ} \mathrm{C}$ was chosen as the processing temperature for the carrots samples based on our previous kinetic study of carrot texture degradation (Peng et al., 2014). The literature reported by Gaze and Brown (1990) studied the thermal resistance of NP C. botulinum type E spores in carrots at $75-90^{\circ} \mathrm{C}$ and reported their D value of 0.48 min at $90^{\circ} \mathrm{C}$, therefore a $6 \mathrm{D}$ process of NP C. botulinum type $\mathrm{E}$ spores in carrots was calculated to be a process of $\mathrm{F}_{90^{\circ} \mathrm{C}}=2.88 \mathrm{~min}$. Thus, two thermal treatment levels were used in this study for carrots processing: one was $\mathrm{F}_{90^{\circ} \mathrm{C}}=3$ min which allows a $6 \mathrm{D}$ reduction of the target pathogen in carrots, the other one was 
$\mathrm{F}_{90^{\circ} \mathrm{C}}=10$ min which is generally considered as an adequate thermal pasteurization process for low-acid foods with a shelf life up to 6 weeks at $5^{\circ} \mathrm{C}$ (ECFF, 2006).

\subsubsection{Microwave processing}

The microwave processing of pre-packaged carrots was performed in a pilot scale MAP system developed at Washington State University (Fig. 1). The MAP system used singlemode $915 \mathrm{MHz}$ cavities, and consisted of four sections (preheating, microwave heating, holding and cooling). More details about the specially designed single-mode cavities can be found in Tang et al. (2015). The preheating and cooling sections also played the roles of loading and unloading, respectively. Each section had a separated water circulation system to control water flow at a constant speed and temperature. The MAP system had two microwave heating cavities in the microwave heating section, with a total microwave power of $14 \mathrm{~kW}$. Food pouches were preloaded in carriers that were transported on a conveyor through the four sections at a constant speed, which was adjusted to achieve the target process (desired F-values). After processing, sample pouches for color and texture measurements were held at $4{ }^{\circ} \mathrm{C}$, and sample pouches for enzyme and carotenoids assay were stored at $-30^{\circ} \mathrm{C}$.

\subsubsection{Conventional hot water processing}

Conventional HW heating was also conducted on the carrot pouches with the MAP system. During the HW processing, the settings of the system pressure and supply water temperatures were the same as for the MAP processing, only the microwave power was turned off. The holding time of food pouches in the holding section was adjusted to 
achieve the target process. After processing, sample pouches were stored at the same conditions as those for the MAP-processed samples.

2.3 Measurement of dielectric properties of carrot samples and selection of model foods Detecting the heating pattern and cold spot inside the prepackaged real foods processed by the MAP system is difficult. Therefore model foods with chemical marker precursors need to be developed to simulate the real foods for heating pattern determination. The dielectric properties of the model food should match those of the real food. Gellan gel has been demonstrated as a model food for microwave pasteurization processes in our previous work, and its dielectric properties can be adjusted to a wide range with different formulations to match with the real products (Zhang et al., 2015). Thus, gellan gel was used as the model food and formulated to match the carrot samples in their dielectric properties.

The dielectric properties of carrot samples were measured using an open-ended coaxial probe connected to an HP 8752C network analyzer (Hewlett Packard Corp., Santa Clara, CA, USA). Drained carrot cuboids were blended into puree before testing. The measurement of the dielectric properties of the carrot puree and the solution $(0.2 \% \mathrm{NaCl}$ with $0.1 \%$ or $1.4 \% \mathrm{CaCl}_{2}$ in distilled water) was carried out following the procedures explained in Peng et al. (2013). The dielectric properties (dielectric constant and loss factor) were measured over a frequency range of $300-3000 \mathrm{MHz}$ at temperatures ranged between 22 and $100^{\circ} \mathrm{C}$. Each measurement was replicated three times. 
2.4 Determination of the heating pattern and cold spot in sample pouches

The heating pattern and cold spots in carrot pouches during microwave processing were determined by a chemical-marker-based computer vision method (Pandit et al., 2007; Zhang et al., 2014). The model food gellan gel formulated in similar dielectric properties as carrot products was added with chemical marker precursors (D-ribose and lysine) and processed by the MAP system under the same processing conditions as those for carrot products. The chemical marker M2 (4-hydroxy-5-methyl-3(2H)-furanone) formed inside the model food through chemical marker precursors caused brown color changes. Positive correlations were established between the color intensity and the accumulative thermal lethality (F-value) as calculated from Eq. (1) (Pandit et al., 2007). The color changes in the gellan gel which reflect the distribution of M-2 and thermal lethality were detected using a computer vision method as described in Pandit et al. (2007). Based on our system design, the configuration of the microwave heating system for each cavity is symmetrical in the thickness direction (vertical line), as a result the electric field distribution is symmetrical, where the middle layer of homogenous samples receives the least energy (Resurreccion, 2015). This is confirmed by our previous work (Luan et al., 2013 \& 2015; Tang et al., 2008; Zhang et al., 2014). Therefore, the microwave pasteurized gellan gel model food was cut horizontally in the middle to get the middle layer images using the computer vision method mentioned above, and the heating pattern and cold spot of the gellan gel were determined. Since the selected model food (gellan gel) could simulate the pouched carrot samples in MW processing for heating pattern determination, the cold spot location of the samples was determined accordingly. 


\subsection{Heat penetration tests}

Heat penetration tests were conducted to determine temperature profiles at the cold spot inside food packages during processing, the information was used to develop the desired process to achieve target microbial inactivation. For the processing of carrot samples, $90^{\circ} \mathrm{C}$ was selected as the pasteurization temperature based on the kinetic results of carrot texture degradation (Peng et al., 2014). As explained in Section 3.3, two thermal treatment levels $\mathrm{F}_{90^{\circ} \mathrm{C}}=3 \mathrm{~min}$ and $\mathrm{F}_{90^{\circ} \mathrm{C}}=10$ min were selected as the desired processes. The calculation of the F value was based on the following equation:

$$
F=\int_{0}^{t} 10^{\frac{T-T_{r e f}}{z}} d t
$$

where $\mathrm{T}\left({ }^{\circ} \mathrm{C}\right)$ is the temperature measured at the cold spot at time $\mathrm{t}$ during process, $\mathrm{T}_{\text {ref }}$ is the reference temperature, and $z$ is the $z$-value of the target bacteria in the products. In the current study, $\mathrm{T}_{r e f}$ was $90^{\circ} \mathrm{C}$ for carrots; $z$ value was $9.84^{\circ} \mathrm{C}$ for NP C. botulinum type $\mathrm{E}$ spores in carrots (Gaze and Brown, 1990).

Considering the moving pouches in the microwave system during processing, mobile metallic temperature sensors, TMI sensors (TMI-USA inc., Reston, VA, USA) were used to record the temperature profiles at the cold spot inside the sample pouches in the current study. More information about the mobile metallic temperature sensors and their use as reliable temperature measurement in continuous microwave processing can be found in a systematic study by Luan et al. (2013 \& 2015). Carrots and solution (0.2\% $\mathrm{NaCl}$ with $0.1 \%$ or $1.4 \% \mathrm{CaCl}_{2}$, w/w) were added at a $1.5: 1$ ratio to bring the net weight 
of each pouch to $227.0 \pm 1.0 \mathrm{~g}$. The TMI sensor tip was inserted into the carrot cuboid, and a microwave transparent frame was used to fix the position of the TMI sensor tip at the cold spot of the sample pouch. Two prepared sample pouches with TMI sensors were loaded to the MAP system and processed along with other sample pouches in each test.

In the heat penetration tests for carrot samples, the system pressure for the MAP system was normal atmosphere; the total power for two microwave heating cavities was $14 \mathrm{~kW}$; the circulating water temperatures were set to $61 / 93 / 93 / 20^{\circ} \mathrm{C}$ for preheating, microwave heating, holding and cooling sections, respectively. The moving speed of the package carrier was adjusted to achieve the target processes. Tests were conducted in duplicates.

\subsection{Quality evaluation}

\subsubsection{Color}

The CIE L* (lightness), a* (redness), and $b^{*}$ (yellowness) color attributes were determined using a computer vision system following the procedures explained in Kong et al. (2007). The color images were analyzed using Adobe PhotoShop. The "L", "a" and "b" values under "Lab color model" from PhotoShop were recorded and then converted to standard CIE L ${ }^{*}, a^{*}$, and $b^{*}$ values using the following equations (Yam and Papadakis, 2004):

$$
\begin{aligned}
& L^{*}=\frac{\text { Ligtness }}{255} \times 100 \\
& a^{*}=\frac{240 a}{255}-120 \\
& b^{*}=\frac{240 b}{255}-120
\end{aligned}
$$

The total color differences $(\Delta \mathrm{E})$ were calculated by the following equations:

$$
\Delta \mathrm{E}=\sqrt{\Delta \mathbf{L}^{* 2}+\Delta \mathbf{a}^{* 2}+\Delta \mathbf{b}^{* 2}}
$$


where the raw samples were used as the control in the calculation of $\Delta \mathrm{E}$.

\subsubsection{Texture}

The firmness of treated carrots was determined using a TA.XT2 Texture analyzer (Stable Micro Systems Ltd., Godalming, UK) fitted with a $25 \mathrm{~mm}$ diameter aluminum cylinder probe following the methods described by Lemmens et al. (2009). The samples were compressed to $70 \%$ strain at a cross head speed of $1 \mathrm{~mm} / \mathrm{s}$. For each test, one piece of sample was placed under the probe. The maximum force (the peak value of the first compression of the sample) was recorded as the indicator of firmness. At least 6 replicates were measured for each treatment condition.

\subsubsection{Pectin methylesterase (PME) activity}

PME was extracted from carrots following the method by Vervoort et al. (2012) with some modification. Ten grams of homogenate was mixed with $0.2 \mathrm{M}$ Tris-HCl buffer containing $1 \mathrm{M} \mathrm{NaCl}(\mathrm{pH} 8.0,1: 1.3 \mathrm{w} / \mathrm{v})$ and stirred at room temperature for $30 \mathrm{~min}$.

The PME activity of the homogenate was quantified as the production of $\mathrm{H}^{+}$during pectin hydrolysis as a function of time at $\mathrm{pH} 7.0$ and $30^{\circ} \mathrm{C}$, following the methods by Anthon \& Barrett (2002) and Anthon et al. (2002). Briefly, $30 \mathrm{ml}$ solution containing $0.25 \mathrm{M} \mathrm{NaCl}$ and $0.25 \%$ citrus pectin was equilibrated to $30^{\circ} \mathrm{C}$ and adjusted to $\mathrm{pH}$ 7.0. One milliliter of homogenate was added to the solution and the $\mathrm{pH}$ was readjusted to 7.0 and maintained at this $\mathrm{pH}$ for $10 \mathrm{~min}$ by the addition of $0.01 \mathrm{~N} \mathrm{NaOH}$. The rate was calculated as $\mu \mathrm{mol}$ of $\mathrm{NaOH}$ consumed over a 10 -min time period. The results were reported as percentages of the unheated control. 


\subsubsection{Carotene analysis}

The extraction of carotene from the raw and processed carrots followed the methods described in Sadler et al. (1990) with modifications. Briefly, 5 g of carrot homogenate was mixed with $50 \mathrm{ml}$ extraction solvent hexane-acetone-ethanol $(2: 1: 1)$ containing $0.1 \%$ BHT and stirred for $20 \mathrm{~min}$. After adding $15 \mathrm{ml}$ milli-Q water to the mixture and stirred for another $10 \mathrm{~min}$, the mixture was centrifuged at $600 \times \mathrm{g}$ for $8 \mathrm{~min}$ to separate the organic layer from the water layer. The organic layer was collected and filtered through a $0.45 \mu \mathrm{m}$ syringe filter as the final extract for assay.

The total carotenoid content of the extract was measured by a spectrophotometer (Pharmacia Biotech Ltd., Cambridge, England) at $450 \mathrm{~nm}$, the maximum absorbance wavelength of $\beta$-carotene. Hexane with $0.1 \%$ BHT was used as a blank. The total carotenoid concentration of the extract was calculated by Beer's law, with the extinction coefficient of $\beta$-carotene in hexane $\mathrm{E}_{1 \mathrm{~cm}}^{1 \%}=2560$. The $\alpha$ - and $\beta$-carotene contents of the carrot samples were determined by the method described by Vervoort et al. (2012), using an Agilent RP-HPLC system with a UV-DAD detector. A YMC Carotenoid column $(150 \times 4.6 \mathrm{~mm}, 5 \mu \mathrm{m})$ was used to separate the carotenoids through linear gradient elution from $100 \%$ solution A ( $81 \%$ methanol, $15 \%$ methyl-t-butyl ether, $4 \%$ milli-Q water) to $100 \%$ solution B (41\% methanol, 55\% methyl-t-butyl ether, 4\% milli-Q water) in 28 min, held for $5 \mathrm{~min}$, then returned to $100 \%$ solution $\mathrm{A}$ and equilibrated for $8 \mathrm{~min}$. The flow rate was $1 \mathrm{ml} / \mathrm{min}$ and the detection wavelength was $450 \mathrm{~nm}$. The standards of $\alpha$ - and $\beta$ carotenes were dissolve in hexane and used for standard curves. 


\subsection{Statistical analysis}

Statistical analysis was conducted using SAS 9.2 (SAS Institute Inc., 2008). One-way analysis of variance (ANOVA) was used for all data. Differences among treatments by means were determined by least significant difference (LSD) multiple comparison test with significant level at $\mathrm{P}<0.05$.

\section{Results and Discussion}

3.1 Dielectric properties of carrot samples and selection of model food

The dielectric properties of food materials reflect the interaction between the foods and electromagnetic energy. They include the dielectric constant (a material's ability to store electromagnetic energy) and dielectric loss factor (a material's ability to convert electromagnetic energy into thermal energy) (Nelson and Kraszewski, 1990). Due to the difficulty to detect the heating pattern and cold spot inside the prepackaged real foods during microwave processing, different model food and chemical marker systems were developed to simulate the real foods for heating pattern determination (Lau et al, 2003; Tang et al., 2008; Wang et al., 2009; Zhang et al., 2014). In the current study, gellan gel was used as the model food for heating pattern determination in MAP processes considering its relative low gelation temperature $\left(<70^{\circ} \mathrm{C}\right)$. Our previous work by Zhang et al. (2015) reported a wide range of dielectric properties of $1 \%$ gellan gel (with $6 \mathrm{mM} \mathrm{Ca}^{2+}$ ) adjusted by various amounts of salt (0-300 $\mathrm{mM} \mathrm{NaCl})$ (Fig. 2). Regression equations relating the dielectric properties with gel formulation and temperature were also developed in that paper to calculate the formulation of gellan gel for a targeting dielectric 
property value. The comparison of dielectric properties of carrot samples (puree and solution) and the model food (1\% gellan gel, $\left.6 \mathrm{mM} \mathrm{Ca}^{2+}\right)$ with different amount of $\mathrm{NaCl}$ are shown in Fig. 2. Overall, the dielectric loss factors of the carrot puree and the solution $\left(0.2 \% \mathrm{NaCl}\right.$ with $0.1 \% \mathrm{CaCl}_{2}$ in distilled water) were very close to each other at each temperature, ranged from 14-34 when the temperature increased from $22^{\circ} \mathrm{C}$ to $100^{\circ} \mathrm{C}$. The dielectric constant of the carrot puree decreased from 72 to 58 when the temperature increased from $22^{\circ} \mathrm{C}$ to $100^{\circ} \mathrm{C}$, and the solution from 76 to 58 . In this case, the pouched samples can be seen as a whole (with similar dielectric properties of the two components). The model food gellan gel could simulate the pouched samples in microwave processing for heating pattern determination. From Fig. 2 it is also seen that the dielectric loss factor of carrot samples at each temperature matched well with the dielectric loss factor of gellan gel added with $40 \mathrm{mM} \mathrm{NaCl}$ calculated by the regression equations developed by Zhang et al. (2015). The calculated dielectric constant values of gellan gel added with 40 $\mathrm{mM} \mathrm{NaCl}$ fell within the range of $\pm 10 \%$ deviation of the real food's dielectric constants, and wouldn't change the heating pattern and cold spot location based on the computer simulation results (Resurreccion, 2015). Therefore, gellan gel (1\% gellan gum, 6mM $\mathrm{Ca}^{2+}$ and $40 \mathrm{mM} \mathrm{NaCl}$ ) has similar dielectric properties as the carrot products, and was used as the model food (with 1\% D-ribose and $0.5 \%$ L-lysine added as chemical marker precursors) for heating pattern and cold spot determination.

\subsection{Heating pattern and cold spot in sample pouches}

Chemical marker method is an effective way for determining the cold spots in foods during a microwave process (Pandit et al., 2007). The heating pattern in carrot pouches 
obtained by the chemical-marker-based computer vision method using gellan gel as the model food is shown in Fig. 3. Based on our previous work by applying computer vision method to heating pattern determination, the gel model food is shown in colors ranging from blue for the coldest temperatures to red for the hottest (Zhang et al., 2014). It can be seen from Fig. 3 that the blue color region showed up around the origin $(0,0) \mathrm{mm}$. Therefore, the cold spot is located at the center of the middle layer in the carrot sample pouch.

\subsection{Heat penetration results}

Processing conditions for both microwave and conventional pasteurization were selected to result in equivalent microbial safety. For the MAP processing, the loaded samples stayed at the preheating section and were preheated at $60^{\circ} \mathrm{C}$ for $20 \mathrm{~min}$, then consecutively passed through the microwave section, holding section $\left(90^{\circ} \mathrm{C}\right)$ and cooling section $\left(20^{\circ} \mathrm{C}\right)$. The moving speed of the package carrier was set at 42 and $39 \mathrm{inch} / \mathrm{min}$ to achieve a process of $\mathrm{F}_{90^{\circ} \mathrm{C}}=3 \mathrm{~min}$ and $\mathrm{F}_{90^{\circ} \mathrm{C}}=10 \mathrm{~min}$, respectively. The total processing time was calculated starting from the sample getting into the microwave section and ending at the sample coming out of the holding section. It was $3.22 \mathrm{~min}$ for $\mathrm{F}_{90^{\circ} \mathrm{C}}=3 \mathrm{~min}$ MAP process and 4.96 min for $\mathrm{F}_{90^{\circ} \mathrm{C}}=10 \mathrm{~min}$ MAP process. Fig. 4A shows the typical temperature profile of the carrot samples recorded by the TIM sensor during microwave processing $\left(\mathrm{F}_{90^{\circ} \mathrm{C}}=10 \mathrm{~min}\right)$.

For conventional hot water processing with the MAP system, the holding time of the samples in the holding section was selected to be 7.80 and 13.96 min to achieve an 
equivalent process with $\mathrm{F}$ value at $90^{\circ} \mathrm{C}$ for $3 \mathrm{~min}$ and $10 \mathrm{~min}$, respectively. Fig. 4B shows the typical temperature-time profile at the cold spot in the sample pouch during the $\mathrm{HW}$ process for a target process of $\mathrm{F}_{90^{\circ} \mathrm{C}}=10 \mathrm{~min}$. The processing parameters to achieve the target processes for carrots by microwave and hot water are summarized in Table 1. It can be seen that for an equivalent process of $\mathrm{F}_{90^{\circ} \mathrm{C}}=3 \mathrm{~min}$, the total processing time by MAP (3.22 min) was reduced by half compared with the HW process $(7.80 \mathrm{~min})$, and by $2 / 3$ compared with the $\mathrm{HW}$ process for an equivalent $\mathrm{F}_{90^{\circ} \mathrm{C}}=10$ min process.

Cook value $C$ is often used to evaluate the impact of a thermal process on food quality by volumetric integration of quality losses throughout the foods. It was calculated from Eq. (6) using time-temperature data obtained in heat penetration test (Tang et al., 2008):

$$
C=\int_{0}^{t} 10^{\frac{T(t)-T_{r e f}}{z}} d t
$$

where $\mathrm{T}_{\text {ref }}$ is $100^{\circ} \mathrm{C}, \mathrm{z}$ is $33.1^{\circ} \mathrm{C}$ based on the average of deterioration of chemical components in foods. The calculation started from samples getting into the preheating section and ended at samples coming out of the cooling section. Since the pouch film was very thin, carrot pieces close to pouch films could be assumed fully exposed to the circulation water as the worst case of quality deterioration during heating processes. Therefore, $C$ values of carrots on the surfaces were estimated using the circulation water temperatures as the product temperatures. $C$ values were also calculated for carrots at the geometric center of the packages using temperature data from the heat penetration tests. The $C$ values for carrots after MAP and HW processing are summarized in Table 1. It can be seen that HW processes resulted in higher $C$ values compared with an equivalent MAP processes. For example, the $C$ value for carrots at the package center was $7.91 \mathrm{~min}$ for the 
HW process, and $4.96 \mathrm{~min}$ for the MAP process with the heating intensity of $\mathrm{F}_{90^{\circ} \mathrm{C}}=10$ min. These results indicated that the overall quality attributes of carrot samples processed by MAP had less thermal deterioration compared with those of the samples treated by traditional HW process at the same heating intensity. Differences of $C$ values between carrots at package center and the surface of pouch film were much smaller for a MAP process compared with a HW process, indicating better quality uniformity in products processed by MAP. Slightly higher $C$ value at package center than on the surface of pouch film was observed in the $\mathrm{F}_{90^{\circ} \mathrm{C}}=10$ min MAP process. This resulted from the accumulative thermal effect during a slower cooling at the package center, suggesting samples locating at the other parts of the pouch might be heated more than those on the surface in a short MAP process.

\subsection{Quality evaluation}

\subsubsection{Color}

The CIE LAB color values of raw and processed carrot cuboids are given in Table 2. Both MAP and HW processes significantly reduced $\mathrm{a}^{*}$ values in the carrot samples, from 48.32 of raw carrots to $38.40-42.90$ of processed ones, $11-20 \%$ reduction compared with the initial value. All carrots processed by MAP had slightly higher a ${ }^{*}$ values than those by HW heating under the same conditions (process intensity and calcium concentration), and significant difference was found in samples with $1.4 \% \mathrm{CaCl}_{2}$ at $\mathrm{F}=10$ min processing level. For $b^{*}$ values, no significant difference was found between the raw and MAPprocessed carrots. However, the difference in $b^{*}$ values was significant between the raw and $\mathrm{HW}$-processed carrots either in $0.1 \% \mathrm{CaCl}_{2}$ at $\mathrm{F}=3$ min processing level or in $1.4 \%$ 
$\mathrm{CaCl}_{2}$ at $\mathrm{F}=10$ min processing level. The overall $\mathrm{L}^{*}$ values of processed carrots remained relatively stable compared to those of raw samples (with values around 61-63), though two MAP-processed and one HW-processed carrots showed significant higher values. The changes in the $\mathrm{a}^{*}$ and $\mathrm{b}^{*}$ values indicate a deterioration of initial intense orange color of the carrots, which were mainly related to the carotenoids that might undergo degradation and isomerization during thermal processing.

Total color differences $(\Delta \mathrm{E})$ between the processed samples and their control (raw carrots) are also summarized in Table 2 . Theoretically speaking, a $\Delta \mathrm{E}$ of 1 represents a justnoticeable color difference to the human eyes under ideal viewing conditions; while $\Delta \mathrm{E}$ values between 2 and 3 could be considered equivalent by some viewers in less than ideal lighting (Vervoort, 2012). From Table 2 it is clear that all the $\Delta \mathrm{E}$ values were higher than 3, suggesting that the color differences between all the processed carrots and the untreated ones are perceptible by human eyes under normal lighting conditions. Carrot cuboids in the $1.4 \% \mathrm{CaCl}_{2}$ solution processed by $\mathrm{HW}$ with $\mathrm{F}_{90^{\circ}} \mathrm{C}=10$ min had the largest $\Delta \mathrm{E}$ value, denoting the least color retention of the carrots. The $\Delta \mathrm{E}$ values of processed carrots varied from 5.54 to 10.32 , and all carrot samples processed by microwave heating have lower $\Delta \mathrm{E}$ values than those by hot water under same conditions, denoting a better color retention. This might be due to the shorter heating time of MAP processing compared with HW processing.

\subsubsection{Texture}


Texture changes of carrots under different processing conditions are shown in Fig. 5. Apparent texture loss was observed in all processed carrot samples compared with the raw samples, and the texture decreased with increased heating intensity. The texture loss of carrot cuboids with $\mathrm{F}_{90^{\circ} \mathrm{C}}=3$ min processing was $27-30 \%$ in $0.1 \% \mathrm{CaCl}_{2}$ and $16-21 \%$ in $1.4 \% \mathrm{CaCl}_{2}$ respectively, while the values were $45-50 \%$ in $0.1 \% \mathrm{CaCl}_{2}$ and $21-25 \%$ in $1.4 \%$ $\mathrm{CaCl}_{2}$ with $\mathrm{F}_{90^{\circ} \mathrm{C}}=10$ min processing. The firming efforts of calcium on texture were obvious from the results, higher concentration of calcium led to a better texture retention. This can be explained by interaction of calcium with the pectins in the cell wall and middle lamella, which improved structural integrity and resulted in a firmer texture. Our results show that increasing calcium concentration from $0.1 \%$ to $1.4 \%$ at $\mathrm{F}_{90^{\circ} \mathrm{C}}=3 \mathrm{~min}$ treatment reduced the texture loss by $1 / 3$, while the value improved to $1 / 2$ at $\mathrm{F}_{90^{\circ} \mathrm{C}}=10$ min treatment. The firming effects of calcium were more apparent at increased thermal processing. Texture loss of processed vegetables mainly attributes to the breakdown of cellular membranes and the cell wall degradation resulting from enzymatic and nonenzymatic transformations of pectic polymers (Anthon et al., 2005; Sila et al., 2008). The breakdown of cellular membranes resulting from turgor loss occurs at a fast phase under high temperature treatment while the changes in cell wall structure, particularly from $\beta$ elimination cleavage of pectins occurs at a slower phase (Anthon et al., 2005). For lowacid carrots, $\beta$-elimination of pectins is the major contributor to texture loss during hightemperature processing. Calcium addition to carrots during the low-temperature preheating period may reduce the extent of $\beta$-elimination which occurs at a slow phase and in pectins with methyl ester group only. This explains that calcium treatment for a longer time and at increased heat intensity is more effective. It can be seen from Fig. 5 
that under the same heating intensity, the texture of carrot samples processed by MAP heating and $\mathrm{HW}$ processing was similar, showing no significant difference.

\subsubsection{PME (pectin methylesterase) activity}

PME is one endogenous enzyme that plays an important role in stabilizing the cell wall structure of carrots. PME can catalyze the de-esterification of pectins, creating binding sites for divalent cations (primarily $\mathrm{Ca}^{2+}$, naturally present in the tissue or added during processing) on the polygalacturonic acid backbone of the pectin to form cross-links between pectin chains, which improves the texture. In the current study, no PME activity was detected in the processed products under the two processing intensities. The results indicate that after a preheating treatment of $60^{\circ} \mathrm{C}$ for $20 \mathrm{~min}$, heating at $90^{\circ} \mathrm{C}$ for even 3.22 min could cause a complete loss of PME activity in the pasteurization processes of carrots. This is in agreement with the published papers that most PMEs are heat sensitive. Anthon and Barrett (2002) studied the kinetics of thermal inactivation of PMEs in carrot

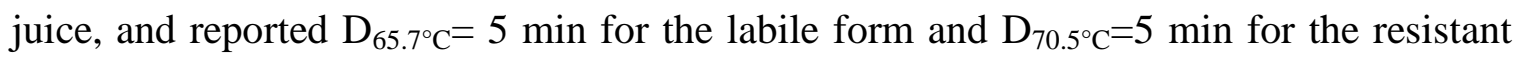
form. Lemmens et al. (2009) studied the thermal pretreatments of carrot pieces using different heating techniques, and reported no PME activity detected in the samples blanched at $90^{\circ} \mathrm{C}$ for $4 \mathrm{~min}$.

\subsubsection{Carotenoids}

Carotenoids are responsible for the bright orange color of carrots, and $\alpha$ - and $\beta$-carotene are the two major carotenoids in carrots. The total carotenoids, $\alpha$ - and $\beta$-carotene contents in raw and processed carrot products are shown in Fig. 6. In raw carrots, the dry weight 
of the total carotenoids, $\alpha$ - and $\beta$-carotene contents are $130.13 \pm 3.35,34.15 \pm 1.04$ and $93.64 \pm 3.12 \mathrm{mg} / 100 \mathrm{~g}$, respectively. Both MAP and HW processing significantly reduced the contents of the total carotenoids, $\alpha$ - and $\beta$-carotene in the final carrot products. Thermal processes for $\mathrm{F}_{90^{\circ} \mathrm{C}}=3$ min caused a loss of $15-23 \%$ in total carotenoids compared with the initial value; for $\mathrm{F}_{90^{\circ} \mathrm{C}}=10 \mathrm{~min}$, the loss was $19-35 \%$. For $\beta$-carotene, the loss was $11-20 \%$ for the processes achieving $\mathrm{F}_{90^{\circ} \mathrm{C}}=3$ min and $17-37 \%$ for the processing of $\mathrm{F}_{90^{\circ} \mathrm{C}}=10 \mathrm{~min}$. The $\alpha$-carotene seems to be more heat sensitive than $\beta$ carotene at the low heat intensity, with $22-30 \%$ loss for a process of $\mathrm{F}_{90^{\circ} \mathrm{C}}=3 \mathrm{~min}$. In most cases, no significant differences were found in the carotenoids for samples processed by MAP and $\mathrm{HW}$ heating. However, for carrots in $1.4 \% \mathrm{CaCl}_{2}$ solution by processing with $\mathrm{F}_{90^{\circ} \mathrm{C}}=10 \mathrm{~min}$, the total carotenoids and $\beta$-carotene losses by MAP heating were larger than HW processing. One possible reason might be the longer time heating of $\mathrm{HW}$ processing causing more cell disruption of carrot tissue, which resulted in an improved extractability of the carotenoids. Vervoort et al. (2012) also observed a decrease of $\alpha$ - and $\beta$-carotene contents in carrot products going from mild pasteurization at $70^{\circ} \mathrm{C}$ to sterilization. However, Knockaert et al. (2011) reported an increased $\beta$-carotene content in sterilized carrots after a process of $\mathrm{F}_{0}=3 \mathrm{~min}$.

\section{Conclusions}

This study demonstrated the applicability of using a $915 \mathrm{MHz}$ single-mode microwaveassisted pasteurization (MAP) system in pasteurizing pre-packaged carrots in brine. Gellan gel (1\% gellan gum, 6mM Ca ${ }^{2+}, 40 \mathrm{mM} \mathrm{NaCl}, 1 \%$ D-ribose and $0.5 \%$ L-lysine) was formulated and chosen as the model food to simulate the carrot samples for heating 
pattern and cold spot determination. The cold spot location detected by a chemicalmarker based computer vision method was at the center of the middle layer in the carrot sample pouch. Two MAP processes $\left(\mathrm{F}_{90^{\circ} \mathrm{C}}=3 \mathrm{~min}\right.$ and $\left.\mathrm{F}_{90^{\circ} \mathrm{C}}=10 \mathrm{~min}\right)$ were successfully established for carrot cuboids in brine (with $\mathrm{NaCl} \& \mathrm{CaCl}_{2}$ added in distilled water) prepackaged in 8-oz polymer pouches, along with conventional HW processes resulting in equivalent microbial safety. The total processing time of a MAP process was greatly reduced compared with an equivalent $\mathrm{HW}$ process (reduced by $1 / 2$ for a process of $\mathrm{F}_{90^{\circ} \mathrm{C}}=$ $3 \mathrm{~min}$ and $2 / 3$ for a process of $\mathrm{F}_{90^{\circ} \mathrm{C}}=10 \mathrm{~min}$ ). MAP process also reduced the cook values and improved the quality uniformity of carrots compared with an equivalent HW process, indicating less thermal deterioration of the overall quality in MAP-processed samples.

Our results showed that the impacts of MW processing on each quality attribute of carrot products depended on the specific quality parameter selected. For color, all carrot samples processed by MAP had lower $\Delta \mathrm{E}$ values and slightly higher a* values than those by HW under same conditions, denoting a better color retention in MAP-processed samples. No significant differences of texture and PME activities were found in carrots processed by MAP and HW under all treatments. In most cases, no significant differences were found in the carotenoids for samples processed by MAP and HW heating. Only for carrots in $1.4 \% \mathrm{CaCl}_{2}$ solution with severe process of $\mathrm{F}_{90^{\circ} \mathrm{C}}=10 \mathrm{~min}$, the $\beta$-carotene loss (also the total carotenoids loss) by MAP heating was larger than HW heating, which was probably caused by improved extractability of the carotenoids due to the longer and more intense HW heating. Since all the quality attributes of pasteurized carrots were tested and compared immediately after processing only, further work should be carried out to 
investigate the quality changes during the shelf life of products. Further systematic research is also needed to optimize MAP processes for improvement in the product quality. Optimized MAP processes should take advantage of short heating time while considering different sensitivities of food quality attributes to thermal degradation.

\section{Acknowledgements}

This research was funded by the US Agriculture and Food Research Initiative of the USDA National Institute of Food and Agriculture (AFRI 2016-68003-24840), and partially by the Fundamental Research Funds for the Central Universities of China (KYZ201655).

\section{References}

Anthon, G.E., Barrett, D.M., 2002. Kinetic parameters for the thermal inactivation of quality-related enzymes in carrots and potatoes. Journal of Agricultural and Food Chemistry 50, 4119-4125.

Anthon, G.E., Blot, L., Barrett, D.M., 2005. Improved firmness in calcified diced tomatoes by temperature activation of pectin methylesterase. Journal of Food Science 70(5), C342-C347.

Anthon, G.E., Sekine, Y., Watanabe, N., Barrett, D.M., 2002. Thermal inactivation of pectin methylesterase, polygalacturonase, and peroxidase in tomato juice. Journal of Agricultural and Food Chemistry 50, 6153-6159. 
Chen, H., Tang, J., Liu, F., 2007. Coupled simulation of an electromagnetic heating process using the finite difference time domain method. Journal of Microwave Powers and Electromagnetic Energy 41(3), 50-68.

ECFF (European Chilled Food Federation). 2006. Recommendations for the production of prepackaged chilled food. Retrieved on Jun 24, 2016, from http://www.ecff.net/images/ECFF_Recommendations_2nd_ed_18_12_06.pdf

Gaze, J.E., Brown, G.D., 1990. Determination of the Heat Resistance of a Strain of NonproteolyticClostridium botulinum Type B and a Strain of Type E, Heated in Cod and Carrot Homogenate Over the Temperature Range 70 to $92^{\circ} \mathrm{C}$. Campden Food and Drink Research Association Technical Memorandum N. 592. Chipping Campden, UK.

Kim, H.J., Taub, I.A., 1993. Intrinsic chemical markers for aseptic processing of particulate foods. Food Technology 47, 91-99.

Knockaert, C., De Roeck, A., Lemmens, L., Van Buggenhout, S., Hendrickx, M., Van Loey, A., 2011. Effect of thermal and high pressure processes on structural and health-related properties of carrots (Daucus carota). Food Chemistry 125, 903-912.

Kong, F., Tang, J., Rasco, B., Crapo, C., Smiley, S., 2007. Quality changes of Salmon (Oncorhynchus gorbuscha) muscle during thermal processing. Journal of Food Science 72, 103-111.

Koskiniemi, C.B., Truong, V.D., Mcfeeters, R.F., Simunovic, J., 2013. Quality evaluation of packaged acidified vegetables subjected to continuous microwave pasteurization. LWT-Food Science and Technology 54, 157-164. 
Lau, M.H., Tang, J., 2002. Pasteurization of pickled asparagus using $915 \mathrm{MHz}$ microwaves. Journal of Food Engineering 51, 283-290.

Lau, H., Tang, J., Taub, I.A., Yang, T.C.S., Edwards, C.G., Mao, R., 2003. Kinetics of chemical marker formation in whey protein gels for studying high temperature short rime microwave sterilization. Journal of Food Engineering 60, 397-405.

Lemmens, L., Tiback, E., Svelander, C., Smout, C., Ahrne, L., Langton, M., Alminger, M., Loey, A.V., Hendrickx, M., 2009. Thermal pretreatments of carrot pieces using different heating techniques: effect on quality related aspects. Innovative Food Science and Emerging Technologies 10, 522-529.

Luan, D., Tang, J., Pedrow, P.D., Liu, F., Tang, Z., 2013. Using mobile metallic temperature sensors in continuous microwave assisted sterilization (MATS) systems. Journal of Food Engineering 119, 552-560.

Luan, D., Tang, J., Pedrow, P.D., Liu, F., Tang, Z., 2015. Performance of mobile metallic temperature sensors in high power microwave heating systems. Journal of Food Engineering 149, 114-122.

Luan, D., Tang, J., Pedrow, P.D., Liu, F., Tang, Z.,2016. Analysis of electric field distribution within a microwave assisted thermal sterilization (MATS) system by computer simulation. Journal of Food Engineering 188, 87-97.

Lucier, G., Lin, B.H., 2007. Factors affecting carrot consumption in the United States. Outlook Report from the Economic Research Service/USDA. No. (VGS-31901): 121.

Nelson, S.O., Kraszewski, A.W., 1990. Dielectric properties of materials and measurement techniques. Drying Technology 8, 1123-1142. 
Pandit, R.B, Tang, J., Liu, F., Pitts, M., 2007. Development of a novel approach to determine heating pattern using computer vision and chemical marker (M-2) yield. Journal of Food Engineering 78, 522-528.

Peng, J., Tang, J., Barrett, D.M., Sablani, S.S., Anderson, N., Powers, J.R., 2015.

Thermal pasteurization of vegetables: critical factors for process design and effects on quality. Critical Reviews in Food Science and Nutrition. DOI:

10.1080/10408398.2015.1082126.

Peng, J., Tang, J., Barrett, D.M., Sablani, S.S., Powers, J., 2014. Kinetics of carrot texture degradation under pasteurization conditions. Journal of Food Engineering 122. 84-91.

Peng, J., Tang, J., Jiao, Y., Bohnet, S.G., Barrett, D.M., 2013. Dielectric properties of tomatoes assisting in the development of microwave pasteurization and sterilization processes. LWT-Food Science and Technology 54, 367-376.

Rastogi, N.K., Nguyen, L.T., Balasubramaniam, V.M., 2008. Effect of pretreatments on carrot texture after thermal and pressure-assisted thermal processing. Journal of Food Engineering 88, 541-547.

Resurreccion, F.P., Luan, D., Tang, J., Liu, F., Tang, Z., Pedrow, P.D., Cavalieri, R. 2015. Effect of changes in microwave frequency on heating patterns of foods in a microwave assisted thermal sterilization system. Journal of Food Engineering 150, $99-105$.

Resurreccion, F.P., Tang, J., Pedrow, P., Cavalieri, R., Liu, F., Tang, Z., 2013. Development of a computer simulation model for processing food in a microwave assisted thermal sterilization (MATS) system. Journal of Food Engineering 118, 406416. 
Sadler, G., Davis, J., Dezman, D., 1990. Rapid extraction of lycopene and $\beta$-carotene from reconstituted tomato paste and pink grapefruit homogenates. Journal of Food Science 55, 1460-1461.

Sila, D.N., Duvetter, T., Roeck, A.D., Verlent, I., Smout, C., Moates, G.K., Hills, B.P., Waldron, K.K., Hendrickx, M., Loey, A.V., 2008. Texture changes of processed fruits and vegetables: potential use of high-pressure processing. Trends in Food Science and Technology 19, 309-319.

Smout, C., Sila, D.N., Vu, T.S., Van Loey, A.M., Hendrickx, M., 2005. Effect of preheating and calcium pre-treatment on pectin structure and thermal texture degradation: a case study on carrots. Journal of Food Engineering 67, 419-425.

Tang, J., 2015. Unlocking potentials of microwaves for food safety and quality. Journal of Food Science 80, E1776-1793.

Tang, Z., Mikhaylenko, G., Liu, F., Mah, J.H., Pandit, R., Younce, F., Tang, J., 2008. Microwave sterilization of sliced beef in gravy in 7 oz trays. Journal of Food Engineering 89, 375-383.

Vervoort, L., Van der Plancken, I., Grauwet, T., Verlinde, T., Matser, A., Hendrickx, M., Van Loey, A., 2012. Thermal versus high pressure processing of carrots: a comparative pilot-scale study on equivalent basis. Innovative Food Science and Emerging Technologies 15, 1-13.

Wang Y., Tang J., Rasco B., Wang S., Alshami, A.A., Kong F., 2009. Using whey protein gel as a model food to study the dielectric heating properties of salmon (Oncorhynchus gorbuscha) fillets. LWT-Food Science and Technology 42, 11741178. 
Yam, K.L., and Papadakis, S.E., 2004. A simple digital imaging method for measuring and analyzing color of food surfaces. Journal of Food Engineering 61, 137-142.

Zhang, W., Luan, D., Tang, J., Sablani, S., Rasco, Lin, H., Liu, F., 2015. Dielectric properties and other physical properties of low-acyl gellan gel as relevant to microwave assisted pasteurization process. Journal of Food Engineering 149, 195203.

Zhang, W., Tang, J., Liu, F., Bohnet, S., Tang, Z., 2014. Chemcial marker M2 (4hydroxy-5-methyl-3(2H)-furanone) formation in egg white gel model for heating pattern determination of microwave-assisted pasteurization processing. Journal of Food Engineering 125, 69-76. 


\section{List of Figure Captions}

Figure 1. Front view of the MAP system at Washington State University.

Figure 2. Dielectric constant (a) and loss factor (b) at $915 \mathrm{MHz}$ for carrot samples and gellan gel with $\mathrm{NaCl}(0-300 \mathrm{mM})$. Data related to gellan gel was adapted from Zhang et al. (2015).

Figure 3. Heating pattern in gellan gel model food (top view, middle layer) processed by a $915 \mathrm{MHz}$ single mode microwave pasteurization system. Colors range from blue for the coldest temperatures to red for the hottest.

Figure 4. Example of temperature-time profiles of the cold spot in the carrot pouch under $\operatorname{MAP}\left(\mathrm{A}, \mathrm{F}_{90^{\circ} \mathrm{C}}=10 \mathrm{~min}\right)$ and $\mathrm{HW}\left(\mathrm{B}, \mathrm{F}_{90^{\circ} \mathrm{C}}=10 \mathrm{~min}\right)$ processing with preheating at $60^{\circ} \mathrm{C}$ for $20 \mathrm{~min}$.

Figure 5. Texture of carrots cuboids under different treatments. Columns labeled with the same letters are not significant different $(\mathrm{p}<0.05)$.

Figure 6. Total carotenoids content, $\alpha$ - and $\beta$-carotene contents in carrot products under different treatments. Columns labeled with the same letters are not significant different $(\mathrm{p}<0.05)$. 


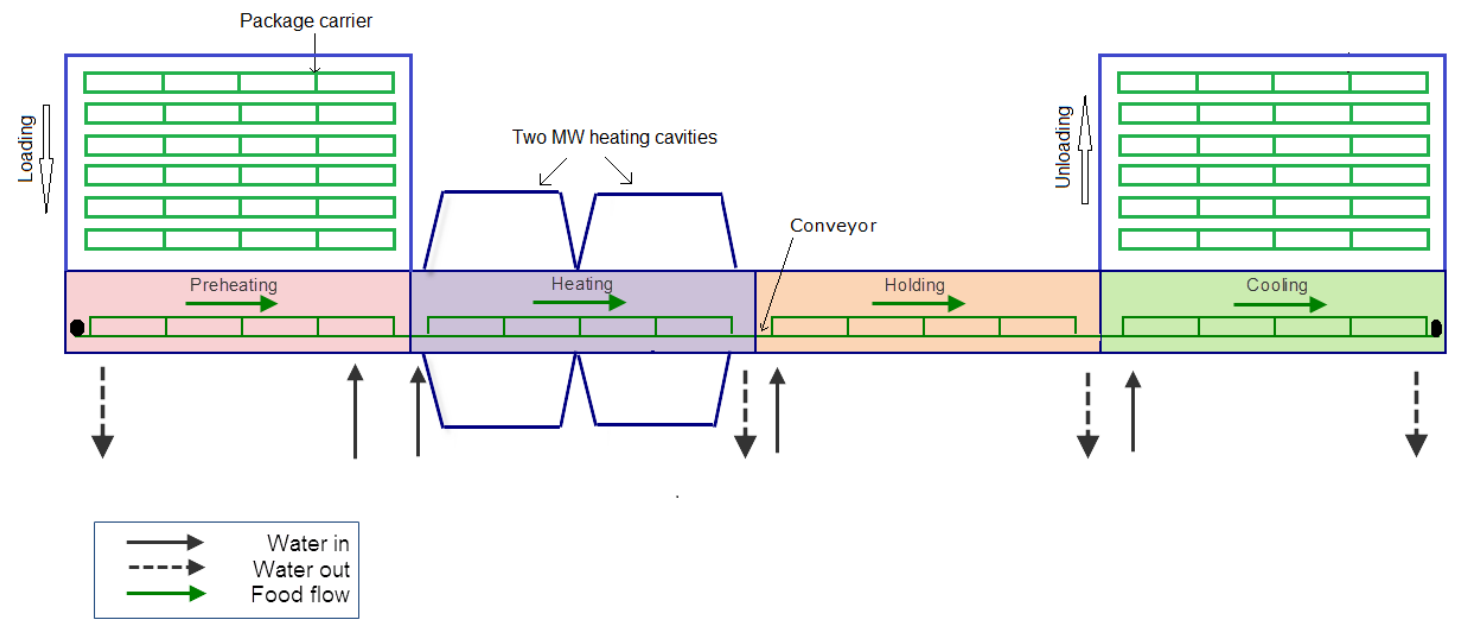

Figure 1. Front view of the MAP system at Washington State University. 

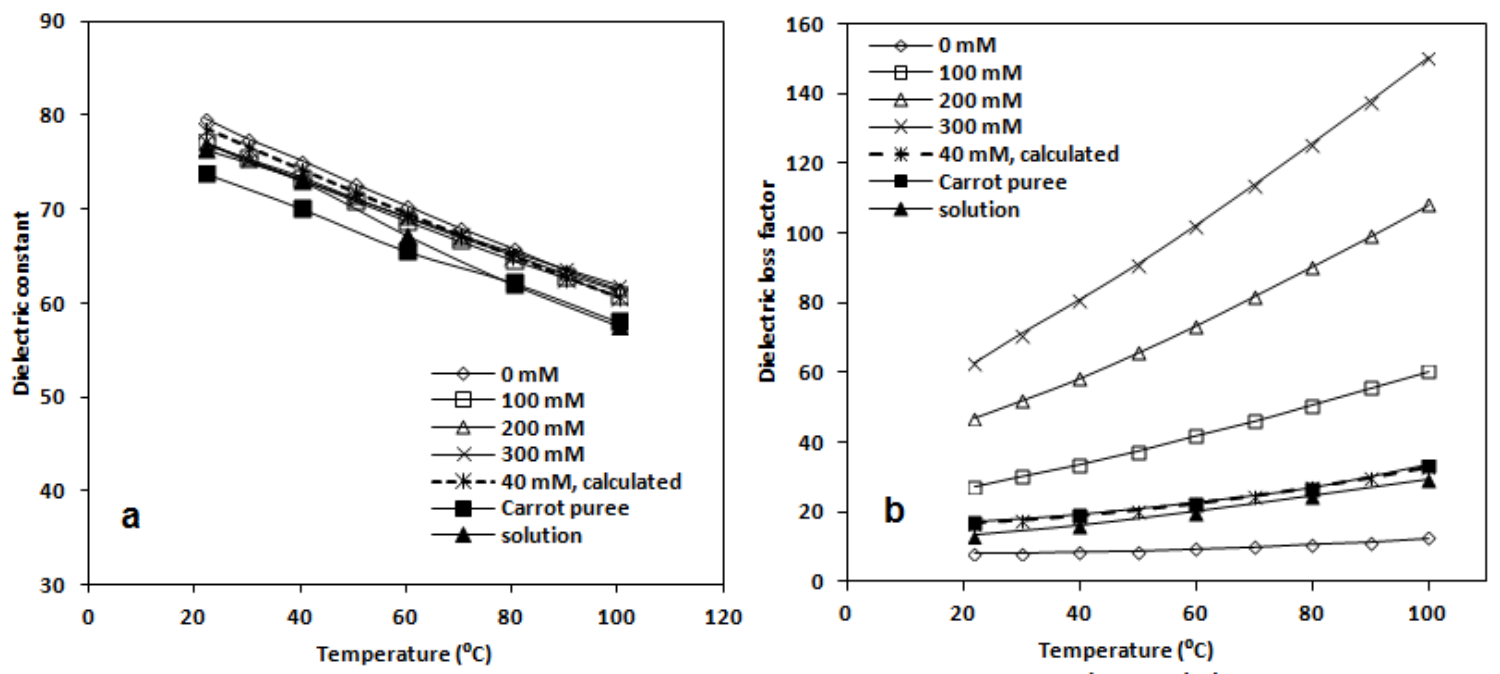

Figure 2. Dielectric constant (a) and loss factor (b) at $915 \mathrm{MHz}$ for carrot samples and gellan gel with $\mathrm{NaCl}(0-300 \mathrm{mM})$. Data related to gellan gel was adapted from Zhang et al. (2015). 


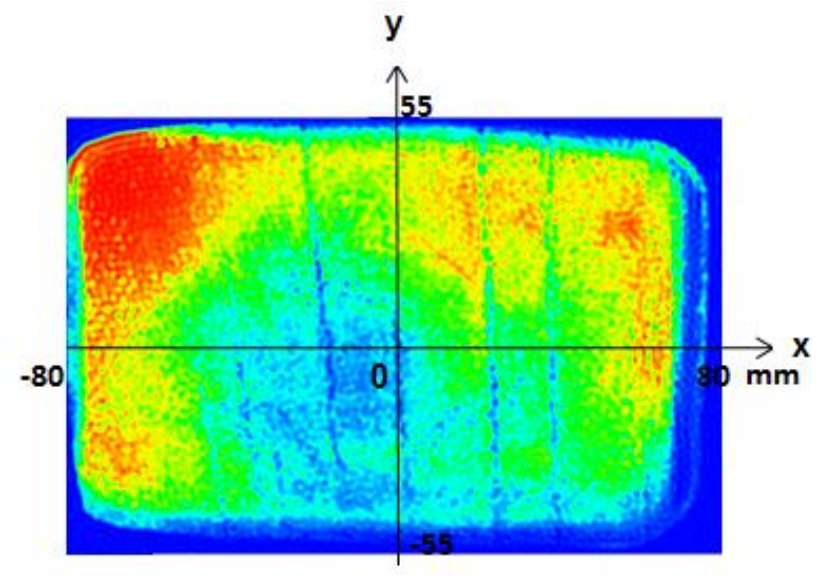

Figure 3. Heating pattern in gellan gel model food (top view, middle layer) processed by a $915 \mathrm{MHz}$ single mode microwave pasteurization system. Colors range from blue for the coldest temperatures to red for the hottest. 


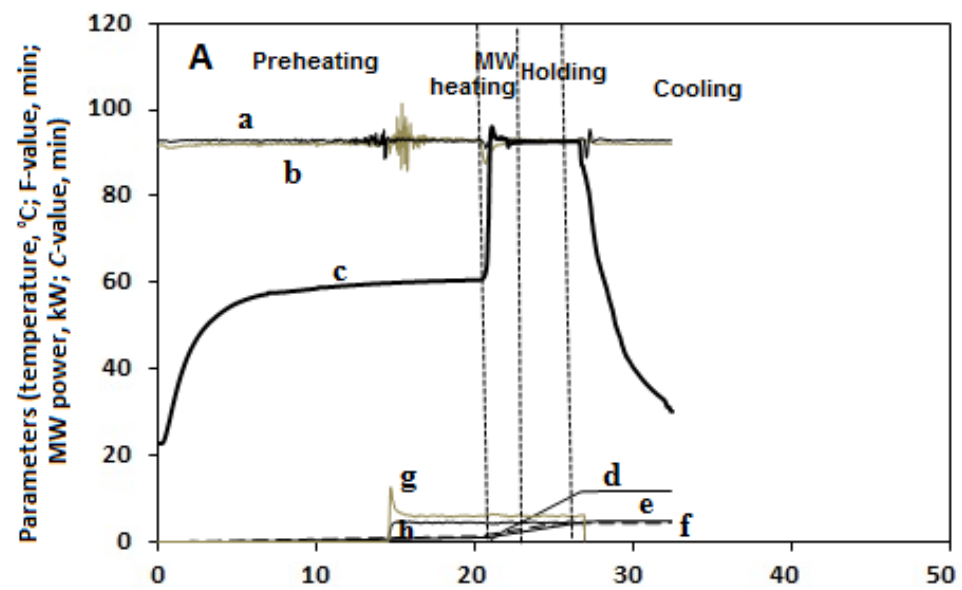

\begin{tabular}{l}
\hline a: inlet water temperature \\
b: outlet water te mperature \\
c: cold spot temperature \\
d: F value at cold spot \\
e: C-value at package center \\
- f: estimated C-value on the \\
surface \\
g: forwarded MW power to \\
cavity 1 \\
h: forwarded MW power to \\
cavity 2
\end{tabular}

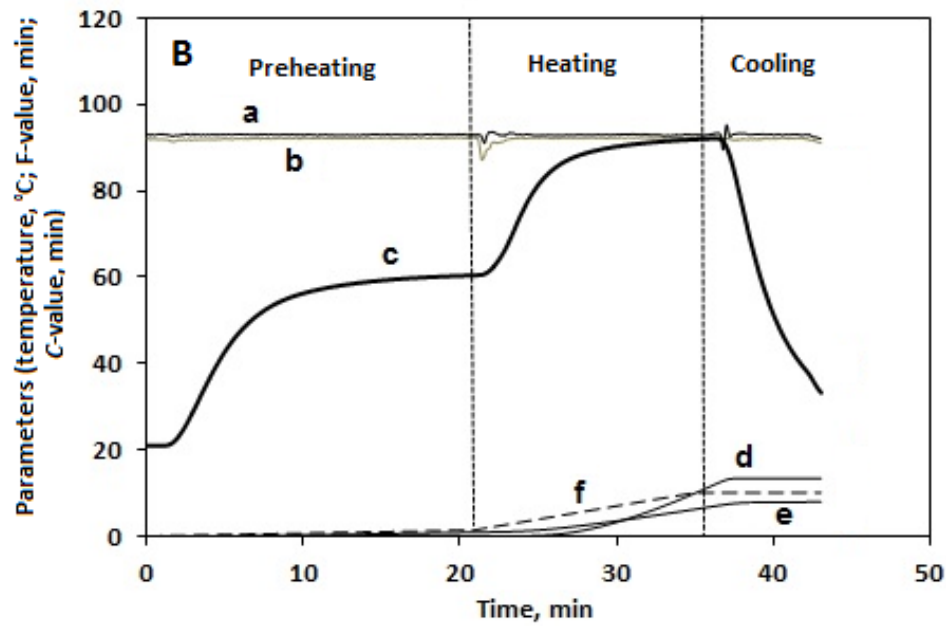

- a: inlet water temperature

b: outlet water temperature

C: cold spot temperature

d: $F$ value at cold spot

e: C-value at package center

$---\cdot f$ : estimated $\mathrm{C}$-value on the surface

Figure 4. Example of temperature-time profiles of the cold spot in the carrot pouch under $\operatorname{MAP}\left(\mathrm{A}, \mathrm{F}_{90^{\circ} \mathrm{C}}=10 \mathrm{~min}\right)$ and $\mathrm{HW}\left(\mathrm{B}, \mathrm{F}_{90^{\circ} \mathrm{C}}=10 \mathrm{~min}\right)$ processing with preheating at $60^{\circ} \mathrm{C}$ for $20 \mathrm{~min}$. 


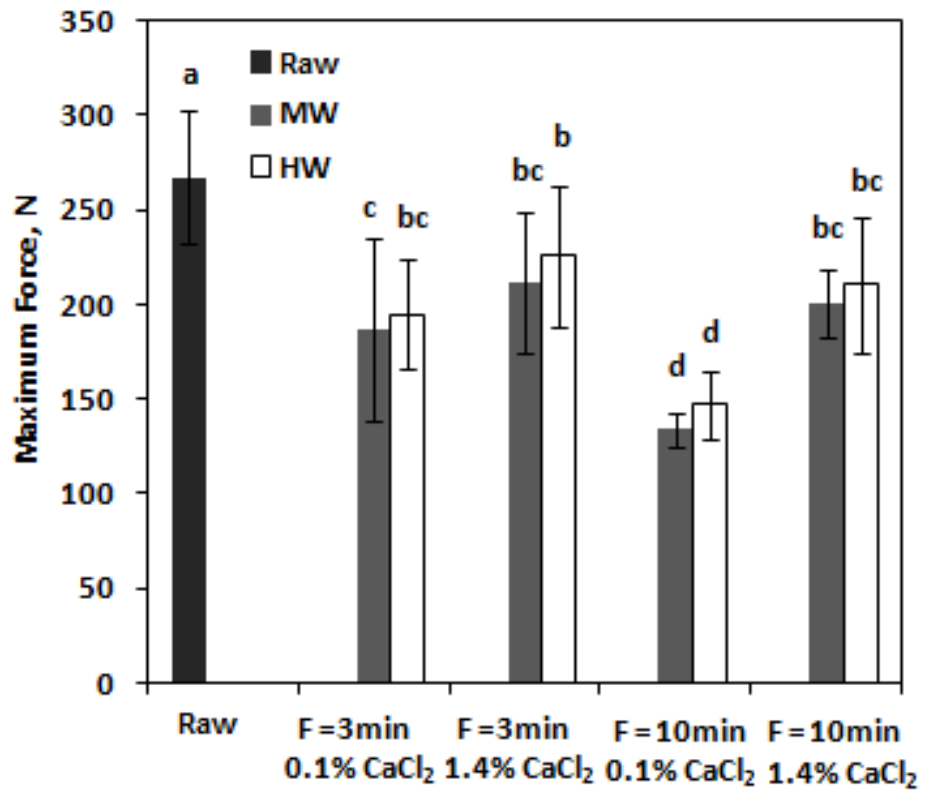

Figure 5. Texture of carrot cuboids under different treatments. Columns labeled with the same letters are not significant different $(\mathrm{p}<0.05)$. 


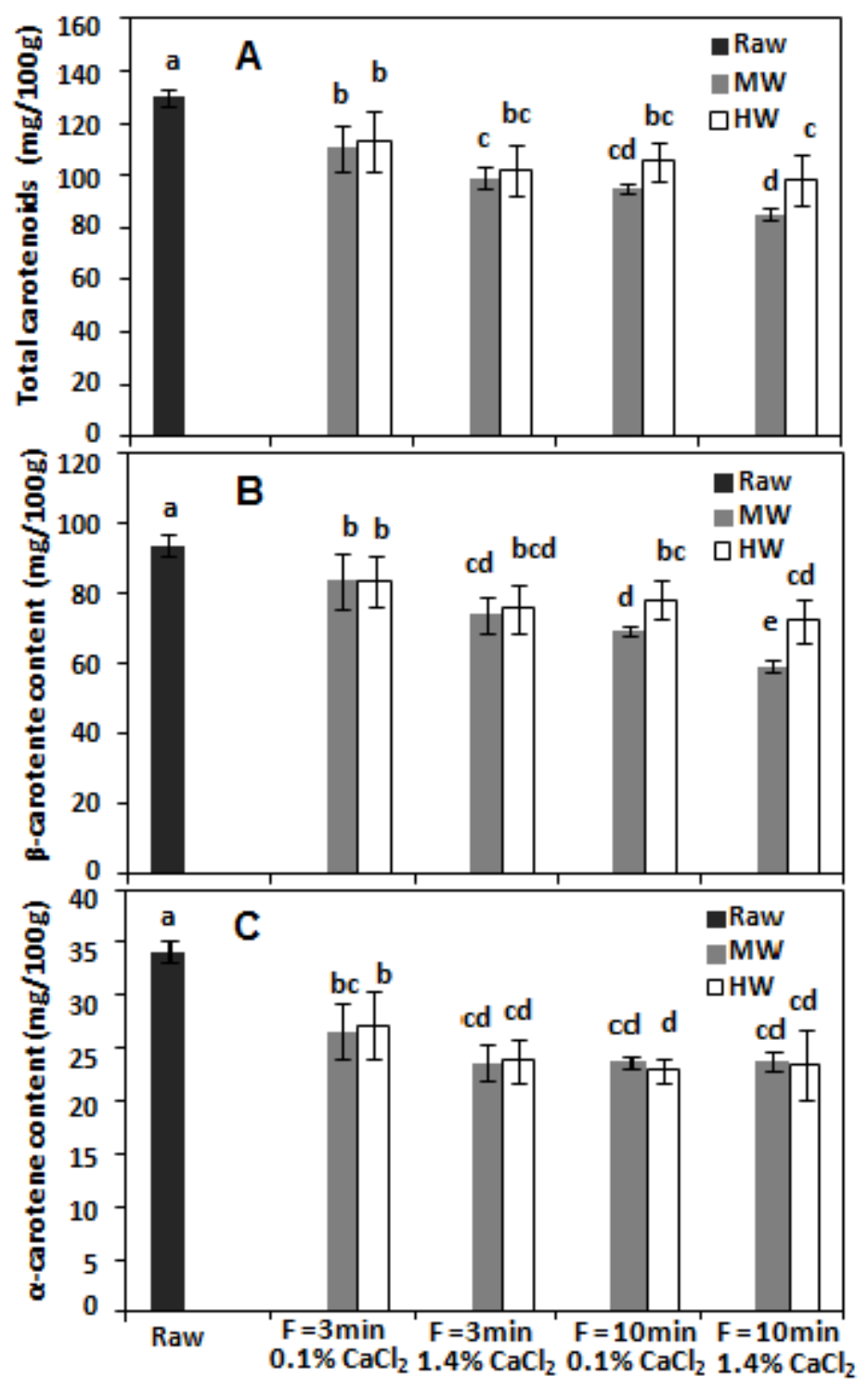

Figure 6. Total carotenoids content, $\alpha$ - and $\beta$-carotene contents in carrot products under different treatments. Columns labeled with the same letters are not significant different $(\mathrm{p}<0.05)$. 
Table 1. Processing conditions for equivalent MAP and conventional HW processes with regard to microbial safety.

\begin{tabular}{llll}
\hline & Processing levels & $\mathrm{F}_{90^{\circ} \mathrm{C}=3 \mathrm{~min}}$ & $\mathrm{~F}_{90^{\circ} \mathrm{C}=10 \mathrm{~min}}$ \\
\hline \multirow{3}{*}{ MAP } & Water temperature setting & $61 / 93 / 93 / 20^{\circ} \mathrm{C}$ & \\
processing & (preheating/MW heating/holding/cooling) & & \\
& Preheating time (min) & 20 & 20 \\
& MW heating time (min) & 1.36 & 1.46 \\
& Holding time (min) & 1.86 & 3.50 \\
& Total processing time (min) & 3.22 & 4.96 \\
& $C_{\text {center }}$ (min) & 3.28 & 4.96 \\
& $C_{\text {surface }}$ (min) & 3.36 & 4.44 \\
HW & & & \\
processing & Preheating time (min) & 20 & 20 \\
& Total processing time (min) & 7.80 & 13.96 \\
& $C_{\text {center }}$ (min) & 4.43 & 7.91 \\
& $C_{\text {surface }}$ (min) & 6.14 & 10.08 \\
\hline
\end{tabular}

$C_{\text {center }}$ denotes the cook value for carrots at the geometric center of the package, and $C_{\text {surface }}$ denotes the estimated the cook value for carrots close to the surface of pouch film. 
Table 2. CIE L*, $a^{*}, b^{*}$ values, and total color differences $(\Delta E)$ of diced carrots under different treatments. The color attributes of raw carrots were used as the control. For each parameter (values in the same column), significant differences $(\mathrm{p}<0.05)$ are indicated with different letters.

\begin{tabular}{|c|c|c|c|c|c|}
\hline \multicolumn{2}{|c|}{ Treatments } & $\mathrm{L}^{*}$ & $a^{*}$ & $b^{*}$ & $\begin{array}{c}\text { Total } \\
\text { color } \\
\text { difference } \\
(\Delta \mathrm{E})\end{array}$ \\
\hline \multicolumn{2}{|c|}{ Untreated } & $61.68 \pm 0.60^{\mathrm{c}}$ & $48.32 \pm 0.57^{\mathrm{a}}$ & $59.51 \pm 0.60^{\mathrm{bc}}$ & \\
\hline \multirow{4}{*}{$\begin{array}{l}0.1 \% \\
\mathrm{CaCl}_{2}\end{array}$} & $\mathrm{~F}_{3 \min }, \mathrm{MAP}$ & $61.15 \pm 1.38^{c}$ & $42.90 \pm 2.14^{\mathrm{b}}$ & $58.55 \pm 1.36^{\mathrm{c}}$ & 5.54 \\
\hline & $\mathrm{F}_{3 \min }, \mathrm{HW}$ & $61.17 \pm 0.95^{\mathrm{c}}$ & $42.84 \pm 3.09^{b}$ & $61.14 \pm 0.70^{\mathrm{a}}$ & 5.74 \\
\hline & $\begin{array}{l}\mathrm{F}_{10 \min } \\
\text { MAP }\end{array}$ & $62.92 \pm 2.06^{\mathrm{ab}}$ & $42.62 \pm 3.23^{b}$ & $59.13 \pm 1.64^{c}$ & 5.84 \\
\hline & $\mathrm{F}_{10 \min }, \mathrm{HW}$ & $61.19 \pm 1.44^{c}$ & $40.16 \pm 2.85^{\mathrm{bc}}$ & $59.17 \pm 1.54^{c}$ & 8.18 \\
\hline \multirow{3}{*}{$\begin{array}{r}1.4 \% \\
\mathrm{CaCl}_{2}\end{array}$} & $\begin{array}{l}F_{3 \min }, \text { MAP } \\
F_{3 \min }, H W\end{array}$ & $\begin{array}{c}63.07 \pm 0.93^{\mathrm{ab}} \\
62.24 \pm 1.75^{\mathrm{abc}}\end{array}$ & $\begin{array}{l}41.84 \pm 2.51^{\mathrm{bc}} \\
39.79 \pm 3.97^{\mathrm{bc}}\end{array}$ & $\begin{array}{l}58.64 \pm 1.45^{\mathrm{c}} \\
60.83 \pm 1.04^{\mathrm{ab}}\end{array}$ & $\begin{array}{l}6.69 \\
8.65\end{array}$ \\
\hline & $\begin{array}{l}\mathrm{F}_{10 \min } \\
\text { MAP }\end{array}$ & $62.16 \pm 0.93^{\mathrm{abc}}$ & $42.26 \pm 3.99^{\mathrm{b}}$ & $58.88 \pm 1.44^{\mathrm{c}}$ & 6.30 \\
\hline & $\mathrm{F}_{10 \mathrm{~min}}, \mathrm{HW}$ & $63.57 \pm 2.07^{\mathrm{a}}$ & $38.40 \pm 3.66^{\mathrm{c}}$ & $61.62 \pm 1.60^{\mathrm{a}}$ & 10.32 \\
\hline
\end{tabular}

